\title{
Idades SHRIMP U-Pb do Complexo Sertânia: Implicações Sobre a Evolução Tectônica da Zona Transversal, Província Borborema
}

\author{
Edilton José dos Santos ${ }^{1}$ (ediltonjsantos@terra.com.br), Allen P. Nutman², Benjamim Bley de Brito Neves ${ }^{3}$ \\ ${ }^{1}$ Departamento de G eologia - Centro de Tecnologia e Geociências - UFPE \\ Av. Acadêmico Hélio Ramos s/n, CEP 50740-530, Recife, PE, BRA \\ ${ }^{2}$ Research School of Earth Sciences - Australian National University, Canberra, AUS \\ ${ }^{3}$ Departamento de Mineralogia e Geotectônica - Instituto de G eociências - USP, São Paulo, SP, BRA
}

Palavras-chave: Província Borborema, Terreno Alto Moxotó, SHRIMP, Paleoproterozóico, Complexo Sertânia.

\begin{abstract}
RESUMO
O Complexo Sertânia é uma seqüência metassedimentar com pequena contribuição metavulcânica, de facies anfibolito alto, que ocorre no Terreno Alto Moxotó, Zona Transversal da Província Borborema. Vários levantamentos geológicos têm incluído esta unidade num complexo gnáissico-migmatítico indiviso, questionando, por decorrência, a subdivisão de terrenos proposta para esse domínio litotectônico. O presente trabalho apresenta as primeiras idades geocronológicas U-Pb SHRIMP em zircão e dados isotópicos Sm-Nd desta unidade. Os dados de campo e microscópicos revelaram a presença de uma fração vulcanoclástica de composição andesítica e dacítica ao lado da dominante componente clástica dessas supracrustais. Por outro lado, as imagens de catodoluminescência dos zircões mostraram cristais bem formados ou pouco arredondados, sugerindo tratar-se de sedimentos pouco transportados. As idades calculadas são médias ponderadas com $95 \%$ de confidência, baseadas em agrupamentos de zircões de mesma geração. Foram obtidas idades em torno de 2,0 Ga, que representam a idade primária de cristalização dos zircões, localmente com sobrecrescimento brasiliano. As rochas metaplutônicas do suposto embasamento situam-se no mesmo intervalo de tempo, indicando uma contemporaneidade com a sedimentação das supracrustais. Os dados isotópicos de $\mathrm{Nd}$ (idade modelo $\mathrm{T}_{\mathrm{DM}}$ e $\boldsymbol{E}_{\mathrm{Nd(t)}}$ ) confirmam a presença de fontes arqueanas e paleoproterozóicas. Esses dados demonstram o contraste entre as supracrustais do Terreno Alto Moxotó com as de outros terrenos da Zona Transversal, de idade meso a neoproterozóicas, o que impede sua correlação e implica numa individualização desse terreno como um compartimento tectônico independente dos demais.
\end{abstract}

Keywords: Borborema Province, Alto Moxotó Terrane, SHRIMP, Paleoproterozoic, Sertânia Complex.

\section{ABSTRACT}

The Sertânia complex in the Alto Moxotó Terrane, Zona Transversal of the Borborema Province, Northeast Brazil, is a metasedimentary sequence with a subordinate metavolcanic component, metamorphosed under upper amphibolite facies conditions. Several previous regional geological surveys have included this rock assemblage in an undivided gneissic-migmatitic complex, due to the lack of a tectonostratigraphic model for this unit. This paper presents the first geochronological zircon $\mathrm{U}-\mathrm{Pb}$ ages (SHRIMP U-Pb ages) and the first $\mathrm{Sm}-\mathrm{Nd}$ isotopic data for this complex. Field and microscopic research reveals the existence of a volcanoclastic fraction of andesitic and dacitic composition, besides the dominant clastic components in these supracrustals. Furthermore, cathodoluminescence images of zircons show well formed little rounded crystals, thus suggesting reduced sediment transport prior to deposition. The calculated ages means with a 95\% confidence level, based on a group of zircons of the same generation plot around $2.0 \mathrm{Ga}$, representing the episode of primary zircon crystallization. Some observed overgrowths testify to an additional Brasiliano overprint ( $c a .0 .6 \mathrm{Ga}$ ). Geochronological data on the supposed meta-plutonic rocks of the same complex point to the same Paleoproterozoic time interval, thus indicating contemporaneity with the sedimentation of the supracrustals. The obtained $\mathrm{Nd}$ model ages and $\boldsymbol{\varepsilon}_{\mathrm{Nd}(\mathrm{t})}$ parameters also confirm a contribution of Archean and Paleoproterozoic sources to these supracrustals rocks. These data clearly demonstrate contrast between the supracrustal rock assemblages of the Alto Moxotó Terrane and the supracrustals of other terranes of the Zona Transversal, which display Meso to Neoproterozoic ages, and imply that this crustal segment represents an independent lithotectonic domain. 


\section{INTRO DUÇÃO}

Dados geocronológicos recentes têm demonstrado que a Província Borborema resultou de uma colagem meso a neoproterozóica de várias subprovíncias ou domínios litotectônicos distintos. Do ponto de vista tectonoestratigráfico, a Província abrange 3 grandes domínios, denominados de Setentrional, Central e Meridional (Van Schmus et al., 1995; Brito Neves et al., 2000). Segundo alguns autores, esses domínios representam uma colagem de domínios litotectônicos menores (Jardim de Sá, 1994; Santos, 1996, 1999), de modo que os mesmos podem ser considerados superdomínios ou superterrenos, os quais são aqui denominados de subprovíncias Setentrionais, subprovíncia Transversal e subprovíncias Meridionais (Figura 1). Alguns domínios, faixas e terrenos que formam esse mosaico crustal da Província Borborema estão mostrados na Figura 1.

A evolução da Subprovíncia Transversal envolveu uma colagem através de dois eventos sucessivos, conhecidos como Cariris Velhos (ca. 1,0 Ga) e Brasiliano (ca. 0,6 Ga). Nela são reconhecidos a faixa brasiliana Cachoeirinha e um conjunto de terrenos pré-brasilianos, descritos como faixa Riacho Gravatá, terrenos Alto Pajeú (TAP), Alto Moxotó (TAM) e Rio Capibaribe (TRC), de estruturação vinculada aos eventos Cariris Velhos e Transamazônico, com retrabalhamento brasiliano. Esse domínio pré-brasiliano inclui diversas sequiências litoestratigráficas, de relações estratigráficas nem sempre claras e idades, em grande parte, inferidas.

Uma dessas seqüências é o Complexo Sertânia, o qual foi descrito originalmente por Santos $(1971,1977)$ na região de Arcoverde (PE), como uma das seqüências litoestratigráficas do denominado Complexo do Alto Moxotó. O Complexo Sertânia é formado por gnaisses e migmatitos de protólito essencialmente sedimentar pelítico, distinguindose de duas outras seqüências, uma de protólito psamítico (São Caetano) e outra vulcano-sedimentar (Feliciano). Esse conjunto de rochas gnáissicas, entretanto, foi sempre mapeado como um único complexo gnáissico-migmatítico, às vezes denominado formalmente de Grupo Monteiro (Gomes et al., 1980), tendo sido considerado como a seqüência inferior da faixa de dobramentos Pajeú-Paraíba por Brito Neves (1975). Posteriormente, essas supracrustais voltaram a ser individualizadas por Veiga Jr \& Ferreira (1990), Wanderley (1990) e Santos (1999), os quais estabeleceram seu status atual de complexo litoestratigráfico independente.

Os mapas geológicos recentes 1:500.000 do Serviço Geológico do Brasil (CPRM) mostram bem a distribuição desta unidade (Figura 2), embora persistam dúvidas em algumas áreas, quanto às suas relações com o Complexo São Caetano, de idade Cariris Velhos. Não existem dados geocronológicos desta unidade, para a qual foram atribuídas ida- des desde paleo até mesoproterozóica. O presente texto apresenta os primeiros dados geocronológicos do Complexo Sertânia, o que contribui para a interpretação tectonoestratigráfica desse importante trato da Província Borborema.

\section{CONTEXTO GEOLÓgICO REgIONAL}

O Complexo Sertânia compreende uma seqüência supracrustal de natureza sedimentar com uma contribuição vulcânica subordinada, metamorfizada na facies anfibolito alto (Santos, 1977). Na sua área tipo, a região de Sertânia (PE) (Figura 2), o complexo homônimo é formado, essencialmente, por granada-biotita gnaisses com ou sem sillimanita, com intercalações de mármore, xisto vulcanoclástico e algum quartzito, rocha calcissilicática e anfibolito. Essas rochas são penetradas por intrusões graníticas tabulares (Cariris Velhos?) e migmatizadas em maior ou menor grau, abrangendo facies estromáticas, freqüentemente dobradas (Fotos 2 a 4), as quais evoluem para tipos schlieren até homófanos.

Nas regiões sul e sudeste de Sumé (PB) (Figura 2), predominam granada-biotita xistos com abundantes intercalações de mármores. A oeste e sudoeste de Sertânia parece haver uma gradação para facies rica em quartzitos, formações ferríferas e metavulcânicas máficas, às vezes descritas como diferentes facies ou complexos. Segundo Santos (1999), o Complexo Sertânia representa a unidade supracrustal característica do TAM, de natureza dominantemente plataformal, a qual distribui-se num trend geral NESW, envolvendo terrenos gnáissico-migmatíticos, muitas vezes referidos como Complexo Floresta. Além disso, ocorrem intrusões tabulares de ortognaisses tonalíticos a trondhjemíticos, recém definidos como suíte Camalaú (Santos et al., 2002) (Figura 2).

Neste Complexo, é reconhecido um evento contracional $\mathrm{D}_{\mathrm{n}}$, gerador de zonas de cisalhamento de baixo ângulo e dobras reviradas, isoclinais e recumbentes, às quais estão associadas um metamorfismo de facies anfibolito alto com anatexia parcial e a colocação de numerosos sheets de granitos leucocráticos. Essa trama gnáissica e migmatítica é redobrada por eventos subseqüentes (eventos $D_{n+1}$ ), os quais produziram novas dobras, que variam de simétricas ou assimétricas mais ou menos apertadas, com plano axial desde vertical até horizontal (Fotos 1 a 4).

O limite do TAM com a faixa Cariris Velhos do TAP tem sido definido como uma nappe migmatítica, a nappe Serra de Jabitacá (Santos, 1999), na qual faixas supracrustais do Complexo Sertânia estão deformadas juntamente com ortognaisses e migmatitos, incluindo lentes e massas de anfibolito, metamáfica com ou sem granada, skarn, metapiroxenito, granulito e metanortosito. O transporte de massa é dirigido para WNW e NW, confirmando o 


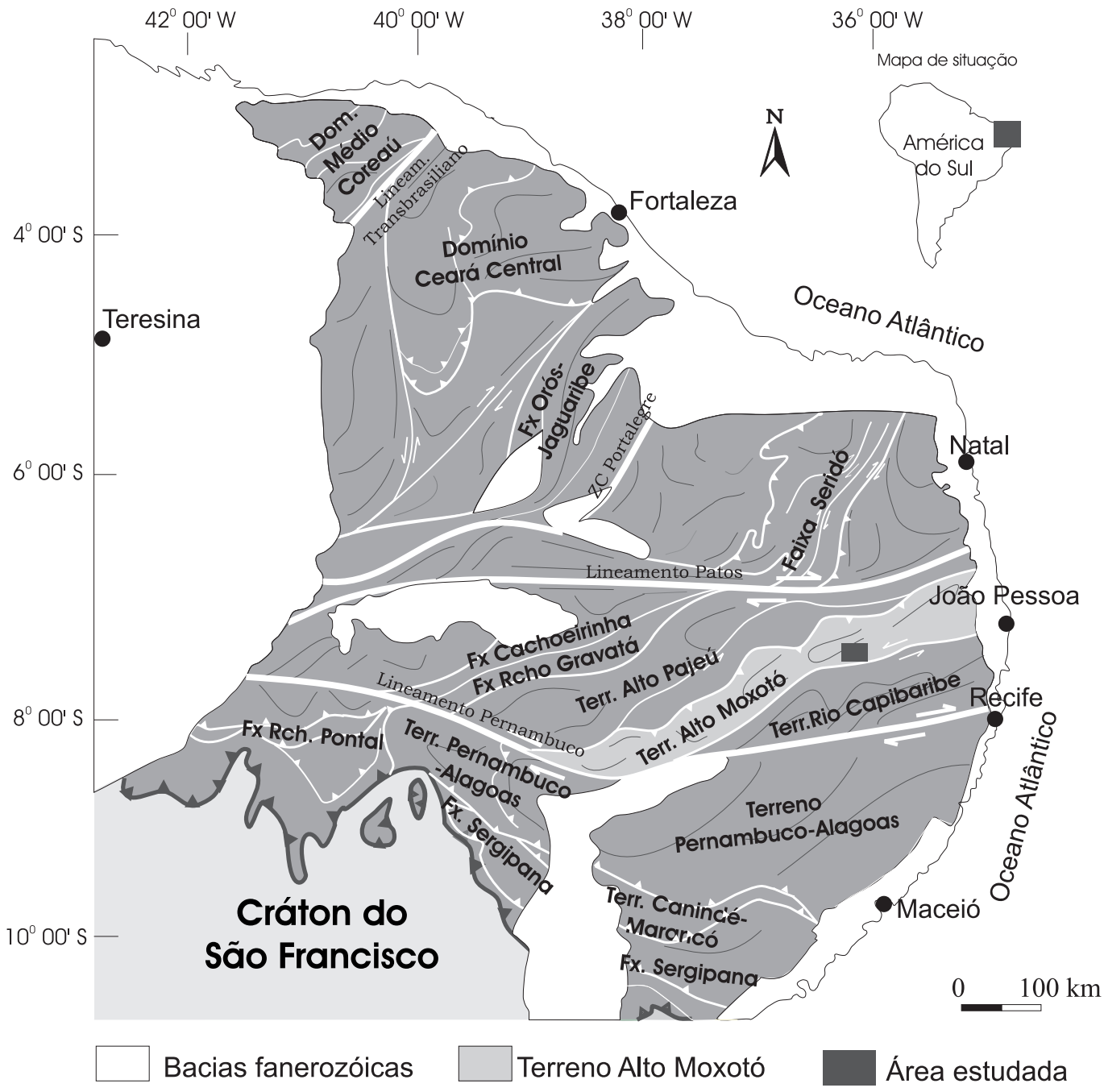

Figura 1. Compartimentação tectônica da Província Borborema, com a localização do Terreno Alto Moxotó e da área estudada. As subprovíncias setentrionais, ao norte do lineamento Patos, possuem grandes extensões de terrenos arqueano e paleoproterozóico (incluindo a faixa estateriana O rós-Jaguaribe) e domínios brasilianos (Médio Coreaú, Ceará Central e Seridó). A subprovíncia Transversal inclui um terreno paleoproterozóico (Alto Moxotó) e faixas de evolução Cariris Velhos e/ou brasiliana (Cachoeirinha, Riacho Gravatá, Alto Pajeú e Rio Capibaribe). As subprovíncias meridionais, ao sul do lineamento Pernambuco, englobam faixas de evolução dominantemente brasiliana (Riacho do Pontal e Sergipana) e domínios brasilianos com protólitos, em parte, esteniano-tonianos (CanindéMarancó e Pernambuco-Alagoas). 


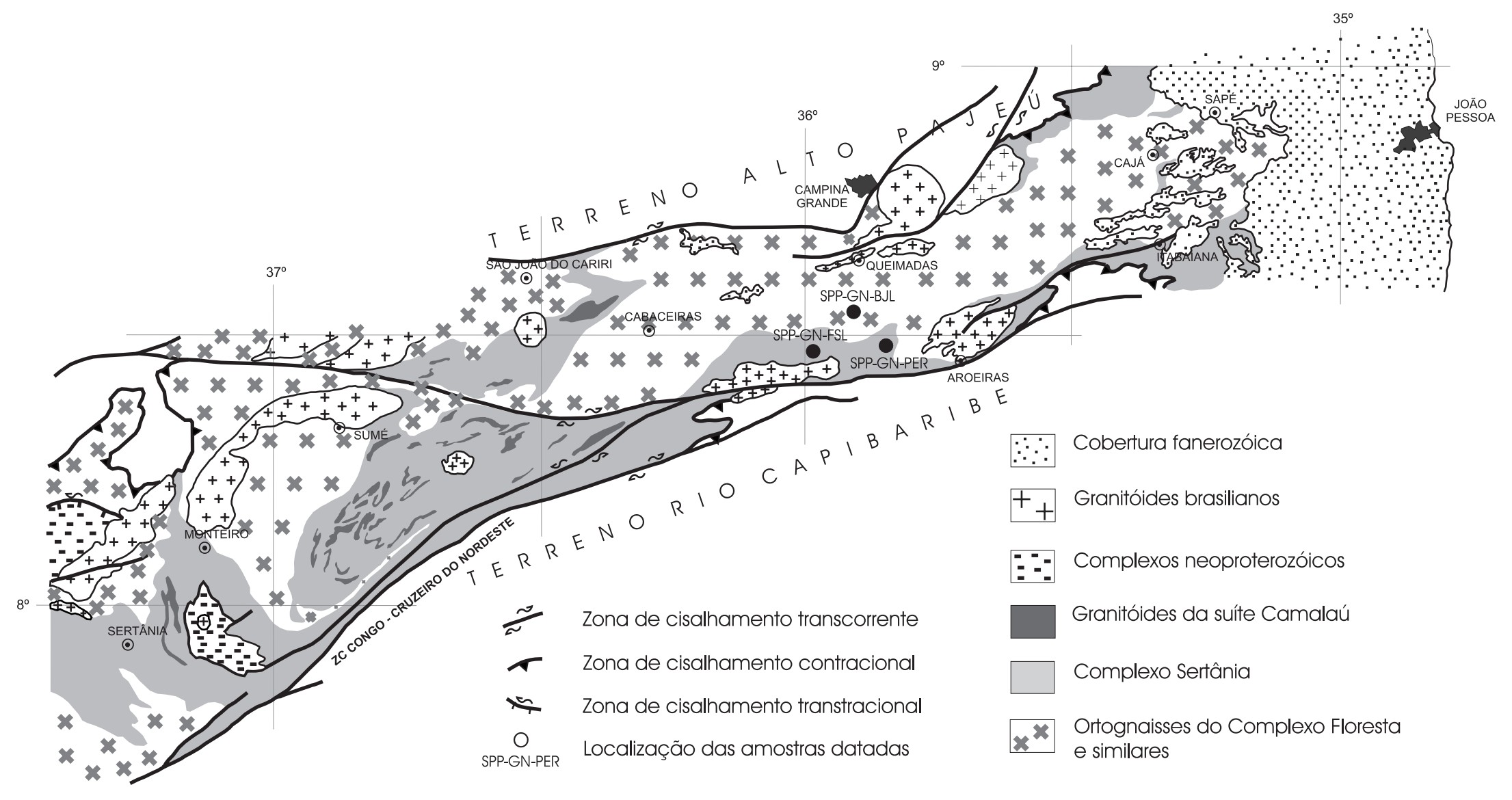

Figura 2. Mapa geológico simplificado do Terreno Alto Moxotó, mostrando a distribuição do Complexo Sertânia e a localização das amostras coletadas (geologia compilada de Santos et al., 2002). 
acavalamento do TAM sobre o TAP. O trend geral dessa megaestrutura é NE-SW, mas as estruturas internas prébrasilianas orientam-se preferencialmente no rumo NW-SE, sugerindo a presença de uma trama antiga, ainda insuficientemente estudada. Há indícios de que essa trama gnáissica $\mathrm{S}_{\mathrm{n}}$, presente nas supracrustais, seja anterior ao empurrão do TAM sobre o TAP, o que é sugerido por complexos padrões de interferência observados, principalmente, nos ortognaisses da nappe Serra de Jabitacá.

Outras evidências são as lentes e blocos de metamáficas, algumas delas antigos diques, que cortaram a foliação $S_{n}$ e foram posteriormente rompidas e rotacionadas pela foliação principal da nappe. A idade dessa tectônica contracional pós-diques ainda é motivo de discussão, sendo interpretada ora como Cariris Velhos, ora como cedobrasiliana.

\section{CARACTERÍSTICAS PETROGRÁFICAS DAS AMOSTRAS}

Para o presente estudo, foram coletadas amostras do Complexo Sertânia e de um complexo metaplutônico, geralmente interpretado como seu embasamento, embora esta relação estratigráfica não esteja comprovada. Essas duas unidades foram estudadas na região de Aroeiras (PB) e a localização das amostras é mostrada na Figura 2. O complexo metaplutônico, muitas vezes chamado de Complexo Floresta, é formado por ortognaisses máficos e félsicos, variadamente migmatizados. A amostra SPP-GN-BJL, coletada na localidade de Barra do João Leite, é um ortognaisse de composição álcali-feldspato granítica, formado essencialmente por quartzo, K-feldspato pertítico e biotita marrom esverdeada, resultante de retrometamorfismo da hornblenda. Os principais acessórios são zircão, apatita e allanita. Não foi observada a presença de clinopiroxênio, mas relictos deste mineral são comuns entre os ortognaisses máficos. Em vários afloramentos na região de Custódia $(\mathrm{PE})$, Santos (1977) descreveu também relictos de ortopiroxênio nesses ortognaisses. A presença deste mineral ao lado do clinopiroxênio, do K-feldspato pertítico e a textura granular desses ortognaisses sugerem que condições de pico metamórfico na facies granulito teriam sido atingidas, sendo as paragêneses subseqüentemente reequilibradas para a facies anfibolito. Alguma actinolita dispersa indica ainda retrometamorfismo de hornblenda na facies anfibolito baixo.

O Complexo Sertânia na área é formado por metapelitos e metagrauvacas, com suposta contribuição vulcanoclástica, como se observa nas amostras das fazendas São Luís (amostra SPP-GN-FSL) e Pereiro (amostras SPP-GN-PER e SPPGN-BXS). A amostra SPP-GN-FSL é um granada-biotitaplagioclásio xisto com cristais maiores e dispersos de quartzo, além dos acessórios titanita, apatita, zircão e opacos. A presença de zircões bem cristalizados e com zonação oscilatória concordante com as bordas dos cristais, conforme observado nas imagens de catodoluminescência (Foto 5), indica a existência de uma componente ígnea nesta rocha. Esse detalhe nos leva a supor que os grãos de quartzo destacados em meio à matriz granolepidoblástica podem ser uma herança de pórfiros vulcânicos ou vulcanoclásticos, embora a textura primária tenha sido totalmente obliterada. A composição mineralógica é comparável à de dacitos e quartzoandesitos, mas a presença de granada demonstra claramente uma contribuição clástica, sugerindo tratar-se primariamente de uma grauvaca vulcanoclástica.

A amostra SPP-GN-BXS, cujos zircões não foram analisados, é um gnaisse de granulação muito grossa, com bastante plagioclásio, quartzo e biotita rica em Ti, com sillimanita local, formada por substituição da biotita. A composição mineralógica é similar à da amostra anterior, isto é, dacítica a quartzoandesítica, com ausência da granada. A biotita foi transformada em rutilo nas bordas dos cristais, sugerindo o desenvolvimento de um incipiente metamorfismo de pressão mais elevada. Por sua vez, a formação da sillimanita e a segregação composicional metamórfica indicam condições de PTX de início da anatexia. A amostra SPP-GN-PER é um migmatito estromático com formação de bandas de meso e neossoma. A mineralogia difere das amostras anteriores pela abundância da microclina pertítica ao lado do quartzo, granada e apatita. Plagioclásio e mirmequita são subordinados. Trata-se de um migmatito de protólito metassedimentar do Complexo Sertânia.

\section{CONDIÇÕES DE OPERAÇÃO SHRIMP, CALIBRACCÕES DOS DADOS E ERROS ANALÍTICOS}

Os dados isotópicos U-Pb em zircão foram obtidos no laboratório SHRIMP I da Australian National University (ANU), usando um spot de $c a .25 \mu \mathrm{m}$ com um feixe de íon primário tipo massa filtrada 02 . Uma resolução de massa de 5500 a 6000 (t medido em termos de $1 \%$ de altura de pico) foi usada para análise. Detalhes dos procedimentos analíticos são apresentados por Stern (1998) e Wiliams (1998). Devido a efeitos como a resistência diferencial entre os elementos das espécies óxido e metálicas, durante a aplicação do feixe, as razões interelementares são calibradas com um padrão, cujas razões são conhecidas por espectrometria de massa por ionização termal e diluição isotópica (IDITMS). Esse método de calibração é explicado em detalhe por Stern (1998) e Williams (1998). Esta razão ${ }^{206} \mathrm{~Pb} /{ }^{238} \mathrm{U}$ tem um componente de erro (usualmente 1,5 a 2,0\%) da calibração das medidas quando se usam os zircões padrões. $\mathrm{O}$ teor de $\mathrm{U}$ foi calibrado em relação a fragmentos de um simples cristal padrão SL13 com 238 ppm de $\mathrm{U}(< \pm 10 \%)$, enquanto a razão $\mathrm{Pb} / \mathrm{U}$ foi calibrada em relação ao padrão multicristal AS57 de 

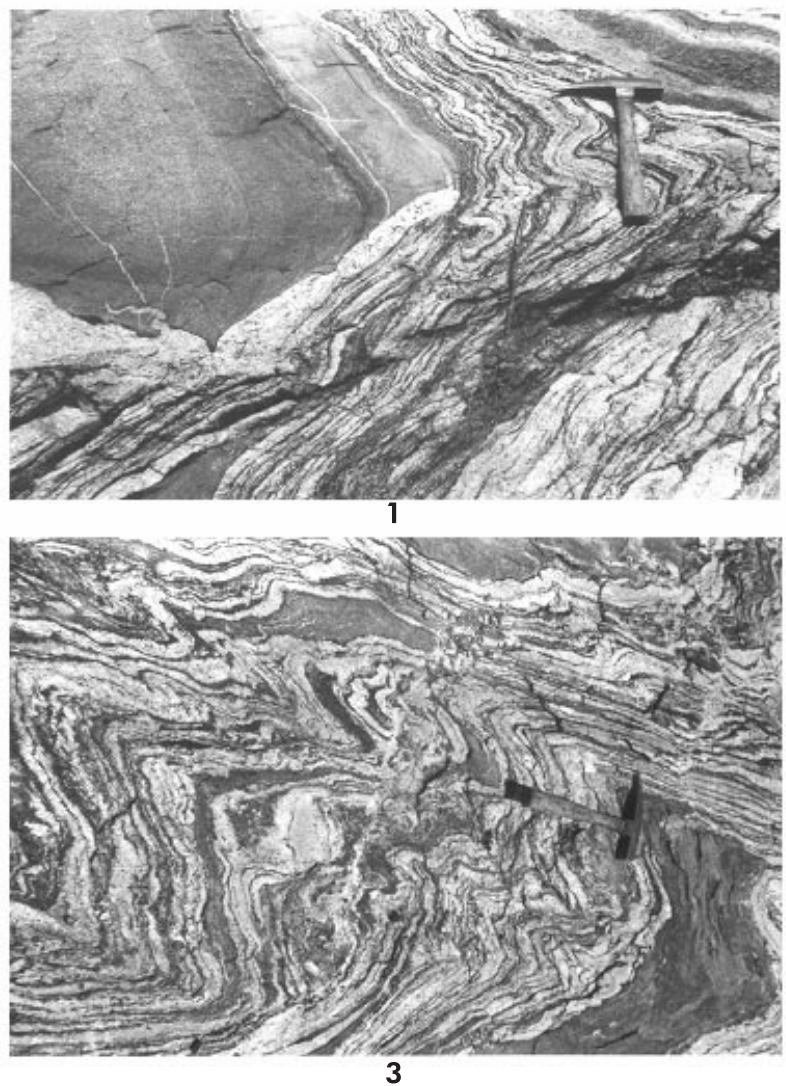

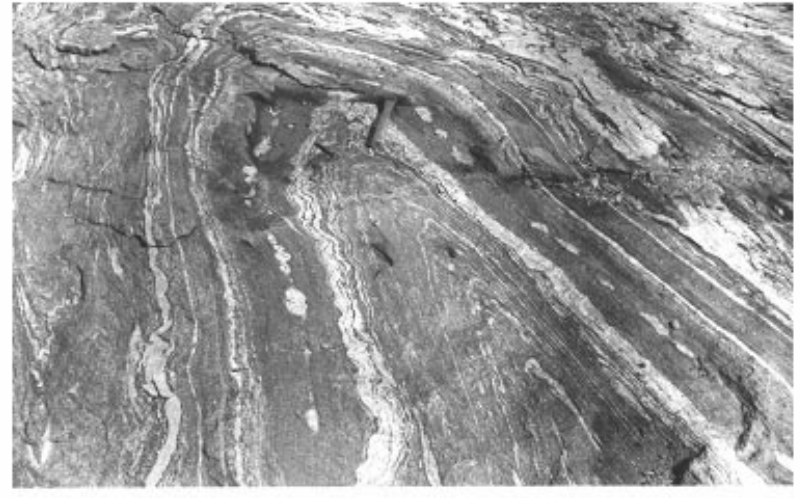

2

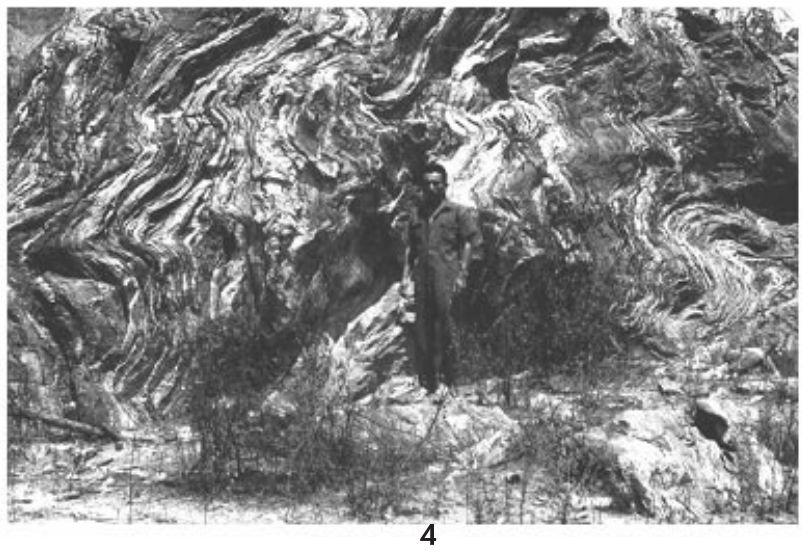

Fotos do Complexo Sertânia na área tipo: 1. Paragnaisse bandado parcialmente migmatizado, com protólito metavulcanoclástico rompido e preservado da migmatização. 2. Migmatito estromático exibindo dobra simétrica $D_{n+1}$ apertada com PA subvertical. 3. Migmatito estromático com intercalações de metavulcanoclásticas, redobrado por $D_{n+1}{ }^{n+1}$ mostrando dobras assimétricas com PA's subparalelos. 4. Migmatito estromático dobrado por eventos $D_{n+1}$, desenvolvendo dobras abertas assimétricas com PA's subhorizontais.

$1100 \mathrm{Ma}$ (Paces \& Miller 1993). Todos os erros levaram em conta as flutuações não lineares nas taxas de contagem iônica, além daquela esperada pela contagem estatística (e.g. Stern 1998).

As constantes de decaimento e o valor atual da razão ${ }^{238} U / 235 \mathrm{U}$ fornecidos por Steiger \& Jager (1977) foram usados para calcular as idades. Para suítes neoproterozóicas com zircões de mais baixo $\mathrm{U}$ ( $=1500 \mathrm{ppm})$, as idades mais confiáveis são aquelas obtidas das razões ${ }^{206} \mathrm{~Pb} /{ }^{238} \mathrm{U}$, seguido da correção para o $\mathrm{Pb}$ comum pelo método do ${ }^{207} \mathrm{~Pb}$ (Compston et al., 1984) e o uso da composição do Pb modelo, para a provável idade dos zircões (Cummings \& Richards, 1977). Para as suítes neoproterozóicas com zircões de mais alto $\mathrm{U}$, nas quais os contrastes da matriz com os zircões padrões podem tornar a calibração do U/Pb irreal, uma maior confidência é fornecida por idades ${ }^{207} \mathrm{~Pb} /{ }^{206} \mathrm{~Pb}$, seguindo-se a correção para o $\mathrm{Pb}$ comum baseada no ${ }^{204} \mathrm{~Pb}$ medido. Para obtenção de idades de zircões mais antigos, é mais confiável usar idades ${ }^{207} \mathrm{~Pb} /{ }^{206} \mathrm{~Pb}$ nos pontos que se aproximam das idades concordantes, seguindo-se a correção para $\mathrm{o} \mathrm{Pb}$ comum baseado no ${ }^{204} \mathrm{~Pb}$ medido.

As idades selecionadas calculadas neste trabalho são médias ponderadas (análise ponderada do inverso da variância, 95\% de confidência e arredondamento para o milhão de anos mais próximo), baseadas no agrupamento de locais, interpretados a partir das imagens CL (catodoluminescência) como pertencentes a uma mesma geração de zircão. As idades foram calculadas utilizando-se o programa Isoplot/EX de Ludwig (1998). Os teores e os locais analisados de Th/U (Tabela 1 - SHRIMP) são discutidos somente quando considerados importantes para a interpretação dos dados isotópicos. Os dados são apresentados na Figura 3, como diagramas Tera-Wasserburg $\operatorname{com}^{238} \mathrm{U} /{ }^{206} \mathrm{~Pb}$ versus ${ }^{207} \mathrm{~Pb} /{ }^{206} \mathrm{~Pb}$. 
Tabela 1. Dados U-Pb SHRIMP dos zircões do Complexo Sertânia.

\begin{tabular}{|c|c|c|c|c|c|c|c|c|c|c|}
\hline $\begin{array}{c}\text { Sigla } \\
\text { do grão }\end{array}$ & $\begin{array}{c}\mathrm{U} \\
(\mathrm{ppm})\end{array}$ & $\begin{array}{c}\text { Th } \\
\text { (ppm) }\end{array}$ & Th/U & $\begin{array}{c}{ }^{206} \mathrm{~Pb} \\
\text { comum \% }\end{array}$ & $\begin{array}{c}\text { Razão } \\
{ }^{238} \mathrm{U} /{ }^{206} \mathrm{~Pb} \\
\end{array}$ & $\begin{array}{c}\text { Razão } \\
{ }^{207} \mathrm{~Pb} /{ }^{206} \mathrm{~Pb}\end{array}$ & $\begin{array}{c}\text { Idade } \\
\mathrm{Ma} \pm 1 \mathrm{~s}\end{array}$ & $\begin{array}{c}\% \\
\text { disc } \\
\end{array}$ & & \\
\hline \multicolumn{11}{|c|}{ Amostra SPP-GN-FSL xisto vulcanoclástico } \\
\hline 1,1 & 140 & 121 & 0,86 & $1,41 \pm 0,38$ & $14,103 \pm 0,817$ & $0,0727 \pm 0,0046$ & $1004 \pm 133$ & -56 & & \\
\hline 2,1 & 314 & 25 & 0,08 & $1,38 \pm 0,19$ & $4,330 \pm 0,159$ & $0,1171 \pm 0,0026$ & $1912 \pm 40$ & -30 & & \\
\hline 3,1 & 199 & 41 & 0,21 & $1,51 \pm 0,14$ & $2,872 \pm 0,099$ & $0,1307 \pm 0,0024$ & $2108 \pm 33$ & -9 & 2108 & 33 \\
\hline 4,1 & 177 & 58 & 0,33 & $1,00 \pm 0,06$ & $2,412 \pm 0,090$ & $0,1334 \pm 0,0027$ & $2143 \pm 36$ & 4 & 2143 & 36 \\
\hline 5,1 & 85 & 35 & 0,42 & $1,50 \pm 0,26$ & $2,602 \pm 0,113$ & $0,1332 \pm 0,0034$ & $2140 \pm 45$ & -2 & 2140 & 45 \\
\hline 6,1 & 158 & 55 & 0,35 & $1,00 \pm 0,02$ & $2,507 \pm 0,126$ & $0,1324 \pm 0,0022$ & $2130 \pm 30$ & 2 & 2130 & 30 \\
\hline 7,1 & 414 & 96 & 0,23 & $0,90 \pm 0,06$ & $2,743 \pm 0,089$ & $0,1318 \pm 0,0017$ & $2121 \pm 22$ & -6 & 2121 & 22 \\
\hline 8,1 & 107 & 12 & 0,11 & $0,82 \pm 0,09$ & $2,719 \pm 0,136$ & $0,1355 \pm 0,0037$ & $2171 \pm 48$ & -7 & & \\
\hline \multirow[t]{2}{*}{9,1} & 134 & 44 & 0,33 & $0,58 \pm 0,03$ & $2,605 \pm 0,158$ & $0,1327 \pm 0,0039$ & $2134 \pm 52$ & -2 & 2134 & 52 \\
\hline & & & & & & & & & $2126 \pm 26$ & $95 \% \quad 0,14$ \\
\hline
\end{tabular}

Amostra SPP-GN-PER gran-biotita xisto metassedimentar

$\begin{array}{llllll}1,1 & 678 & 5 & 0,01 & 1,00 \pm 0,02 & 2,704 \pm 0,087\end{array}$

$\begin{array}{llllll}2,1 & 179 & 52 & 0,29 & 2,55 \pm 0,10 & 2,662 \pm 0,080\end{array}$

$\begin{array}{llllll}3,1 & 316 & 42 & 0,13 & 0,27 \pm 0,06 & 3,003 \pm 0,067\end{array}$

$\begin{array}{llllll}4,1 & 249 & 44 & 0,18 & 1,95 \pm 0,09 & 2,764 \pm 0,101\end{array}$

$\begin{array}{llllll}5,1 & 258 & 243 & 0,94 & 1,12 \pm 0,05 & 2,456 \pm 0,042\end{array}$

$\begin{array}{llllll}6,1 & 765 & 87 & 0,11 & 1,82 \pm 0,02 & 2,795 \pm 0,046\end{array}$

$\begin{array}{llllll}7,1 & 698 & 74 & 0,11 & 2,50 \pm 0,02 & 2,683 \pm 0,055\end{array}$

$\begin{array}{llllll}8,1 & 759 & 36 & 0,05 & 1,00 \pm 0,02 & 2,974 \pm 0,064\end{array}$

$\begin{array}{llllll}9,1 & 172 & 2 & 0,01 & 0,44 \pm 0,03 & 10,196 \pm 0,220\end{array}$

$\begin{array}{llllll}10,1 & 458 & 75 & 0,16 & 1,39 \pm 0,05 & 2,809 \pm 0,100\end{array}$

$\begin{array}{llllll}11,1 & 152 & 54 & 0,35 & 1,15 \pm 0,09 & 2,810 \pm 0,061\end{array}$

$\begin{array}{llllll}12,1 & 227 & 11 & 0,05 & 3,30 \pm 0,37 & 10,836 \pm 0,206\end{array}$

$\begin{array}{llllll}12,2 & 272 & 38 & 0,14 & 1,87 \pm 0,07 & 2,475 \pm 0,073\end{array}$

$\begin{array}{llllll}13,1 & 54 & 26 & 0,48 & 1,26 \pm 0,31 & 3,811 \pm 0,147\end{array}$

$14,1 \quad 284 \quad 42 \quad 0,15 \quad 2,13 \pm 0,06 \quad 3,172 \pm 0,099$

$0,1219 \pm 0,0035 \quad 1984 \pm 52 \quad 2$

$0,1234 \pm 0,0049 \quad 2006 \pm 72 \quad 3$

$0,1196 \pm 0,0020 \quad 1950 \pm 30 \quad-5$

$0,1234 \pm 0,0046 \quad 2006 \pm 68 \quad-1$

$0,1378 \pm 0,0010 \quad 2200 \pm 12 \quad 0$

$0,1225 \pm 0,0011 \quad 1994 \pm 16 \quad-1$

$0,1280 \pm 0,0013 \quad 2070 \pm 18 \quad-1$

$0,1191 \pm 0,0024 \quad 1943 \pm 37 \quad-4$

$0,0610 \pm 0,0025 \quad 638 \pm 92 \quad-6$

$0,1232 \pm 0,0061 \quad 2003 \pm 91 \quad-2$

$0,1222 \pm 0,0024 \quad 1988 \pm 35 \quad-1$

$0,0560 \pm 0,0047 \quad 453 \pm 197 \quad 26$

$0,1257 \pm 0,0039 \quad 2039 \pm 56 \quad 7$

$0,1182 \pm 0,0630 \quad 1930 \pm 98 \quad-22$

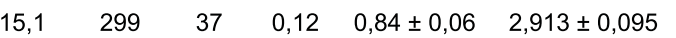

$0,1144 \pm 0,0026$

$0,1206 \pm 0,0050$

$1870 \pm 42 \quad-6$

Amostra SPP-GN-BJL ortognaisse

$\begin{array}{llllllll}9,1 & 172 & 2 & 0,01 & 0,80 \pm 0,26 & 10,195 \pm 0,220 & 0,0611 \pm 0,0025 & 602 \pm 12\end{array}$

$\begin{array}{llllllll}12,1 & 227 & 11 & 0,05 & 2,93 \pm 0,03 & 10,705 \pm 0,200 & 0,0675 \pm 0,0029 & 571 \pm 10\end{array}$

$\begin{array}{llllllll}1,1 & 376 & 64 & 0,17 & 0,27 \pm 0,05 & 3,620 \pm 0,159 & 0,1177 \pm 0,0027 & 1921 \pm 41\end{array}$

$\begin{array}{llllll}1,2 & 609 & 43 & 0,07 & 0,16 \pm 0,04 & 3,208 \pm 0,142\end{array}$

$\begin{array}{llllll}2,1 & 491 & 77 & 0,16 & 0,08 \pm 0,03 & 2,933 \pm 0,092\end{array}$

$\begin{array}{llllll}3,1 & 413 & 90 & 0,22 & 1,44 \pm 0,07 & 2,907 \pm 0,068\end{array}$

$\begin{array}{llllll}3,2 & 332 & 89 & 0,27 & 0,21 \pm 0,06 & 2,804 \pm 0,073\end{array}$

$\begin{array}{llllll}4,1 & 516 & 119 & 0,23 & 0,04 \pm 0,02 & 2,818 \pm 0,077\end{array}$

$\begin{array}{llllll}5,1 & 983 & 21 & 0,02 & 0,69 \pm 0,15 & 4,569 \pm 0,125\end{array}$

$0,1223 \pm 0,0062$

$0,1262 \pm 0,0044$

$0,1239 \pm 0,0011$

$0,1203 \pm 0,0023$

$0,1237 \pm 0,0011$

$0,1148 \pm 0,0018$

$\begin{array}{lllllllll}6,1 & 257 & 76 & 0,29 & 2,30 \pm 0,56 & 3,340 \pm 0,121 & 0,1176 \pm 0,0061 & 1920 \pm 95 & -12\end{array}$

$1990 \pm 93-18$

$\begin{array}{ll}1990 \pm 93 & -12 \\ 2045 \pm 63 & -7\end{array}$

2045

$2013 \pm 15 \quad-5 \quad 2013$

$1961 \pm 35 \quad-1 \quad 1961$

$2010 \pm 16 \quad-3 \quad 2010$

$1877 \pm 29-32$

$2016 \pm 27 \quad 393 \pm 150$

Os dados ${ }^{207} \mathrm{~Pb} /{ }^{206} \mathrm{~Pb}$ foram corrigidos para o $\mathrm{Pb}$ comum, usando-se o ${ }^{204} \mathrm{~Pb}$ medido, corrigido para as razões isotópicas tabeladas

\section{DADOS GEOCRONOLÓGICOS}

O Complexo Sertânia foi datado através dos afloramentos das fazendas São Luís e Pereiro, descritos anteriormente. A amostra SPP-GN-FSL forneceu principalmente zircões prismáticos, com mais de $200 \mu \mathrm{m}$ de comprimento. Em imagens CL, muitos cristais mostram zonação oscilatória subconcordante ao exterior dos grãos. Eles comumente apresentam finos intercrescimentos parciais, os quais aparecem límpidos e homogêneos nessas imagens CL (e. g. grãos 8 e 9 da Foto 5). Uma minoria dos grãos mostra zonação oscilatória fortemente truncada nos limites dos grãos. O grão 7 é um exemplo desse caso (Foto 5), o qual tem uma fina auréola parcial de zircão homogêneo. Nove análises foram realizadas sobre os 9 grãos (Tabela 1, Figura 3a).

Todas as 6 análises do zircão com zonação oscilatória forneceram uma idade média ponderada de ${ }^{207} \mathrm{~Pb} / 206 \mathrm{~Pb}$ de $2126 \pm 26 \mathrm{Ma}$ (95\% de confidência, MSWD =0,14). A análise 8.1 de uma auréola homogênea límpida forneceu idades dentro do erro deste valor, enquanto que as análises 1.1 e 2.1 também de auréolas límpidas, forneceram idades discordantes mais jovens (Tabela 1). A amostra é claramente domina- 


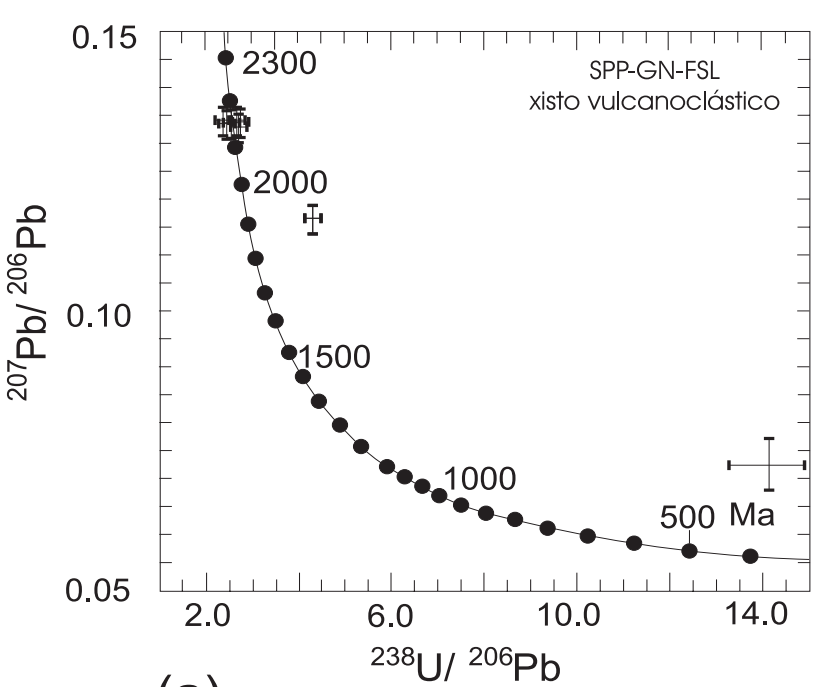

(a)

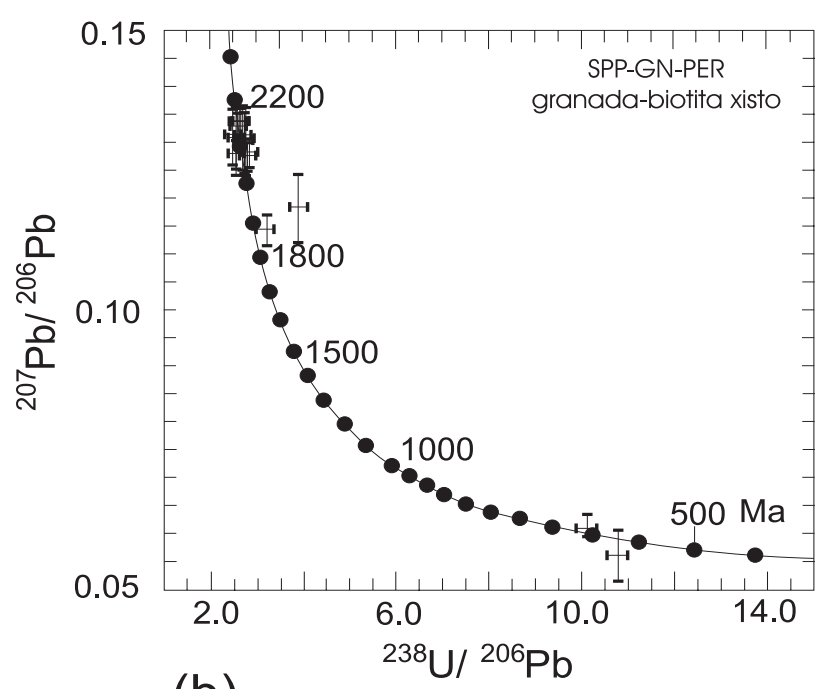

(b)

Figura 3. Diagramas Tera-Wasserburg das amostras do Complexo Sertânia: a - xisto vulcanoclástico da Fazenda São Luís, mostrando uma concentração entre 2100 e 2200 Ma; b - granada-biotita xisto (metassedimento) da Fazenda Pereiro, mostrando um certo espalhamento de pontos entre 1950 e $2100 \mathrm{Ma}$.

da por zircões paleoproterozóicos de origem ígnea e idade restrita, os quais foram afetados por metamorfismo subsequiente e distúrbio isotópico, no evento Brasiliano.

A amostra SPP-GN-PER contém zircões ovais a prismáticos algo arredondados, com comprimento acima de $\sim 250 \mu \mathrm{m}$. Em imagens CL, muitos grãos mostram zonação oscilatória, que é geralmente subconcordante com o exterior dos grãos, embora em alguns casos (e. $g$. grão 8.1, Foto 6) ela seja truncada. Alguns grãos apresentam sobrecrescimento, o qual aparece como zircão homogêneo a levemente oscilatório em imagens CL (e. g. grãos 12.1 e 5.1, Foto 6). Dezesseis análises foram realizadas sobre 15 grãos (Tabela 1). A maioria dos locais sobre zircão zonado oscilatório forneceu idades ${ }^{207} \mathrm{~Pb} /{ }^{206} \mathrm{~Pb}$ concordantes ou próximas, com valores entre 2200 e 1950 Ma (Figura 3b). Esses grãos são interpretados como sendo derivados de um terreno paleoproterozóico dominado por rochas formadas em um curto período de tempo. Considerando-se a aparente falta de abrasão desses grãos, eles são, provavelmente, de um sistema sedimentar com reduzido transporte. Duas análises de sobrecrescimentos (12.1 e 9.1, Tabela 1, Foto 6) forneceram idades muito mais jovens. Embora essas idades não forneçam um dado preciso, elas claramente indicam um sobrecrescimento de zircão durante o metamorfismo neoproterozóico.

O complexo metaplutônico, correlacionado ao Complexo Floresta, foi datado para comparação. Os dados da amostra SPP-GN-BJL (8 análises) produziram dois modelos. O primeiro mostra um alinhamento de todos os pontos, cuja regressão aponta para dois interceptos, de $2016 \pm 27$ Ma e $393 \pm 150 \mathrm{Ma}$, com MSWD = 0,6 (Figura 4). O modelo alternativo reúne as quatro análises mais concordantes, fornecendo uma idade de média ponderada ${ }^{207} \mathrm{~Pb} /{ }^{206} \mathrm{~Pb}$ de $2008 \pm 21 \mathrm{Ma}$, com 95\% de confidência e MSWD =0,8. Esses dados confirmam que o complexo metaplutônico possui a mesma idade das supracrustais, em torno de 2000 Ma, que coincide com idades U-Pb concórdia obtidas em outras amostras do Terreno Alto Moxotó (Brito Neves et al., 2001). A idade de intercepto inferior, aparentemente, não tem significado geológico.

A Tabela 2 mostra alguns dados Sm-Nd do Complexo Sertânia, obtidos em amostras coletadas em várias localidades do TAM, incluindo a área estudada. A Figura 5 exibe a evolução isotópica do $\mathrm{Nd}$ destas rochas. Observa-se que o sillimanita-biotita gnaisse de Aroeiras (SPP-GN-Bgx), o gnaisse da Fazenda São Luís e a biotita gnaisse de Sertânia (SPP-Gn-SERT3), área tipo do complexo, apresentaram idades modelos paleoproterozóicas (2,47 e 2,48 Ga respectivamente). As demais amostras possuem idade modelo $\mathrm{Nd} \mathrm{T}_{\mathrm{DM}}$ arqueanas (entre 2,69 até 2,74 Ga), com valores de $\boldsymbol{E}_{\mathrm{Nd}(\mathrm{t})}$ negativos, indicando que já representam crosta retrabalhada. Brito Neves et al. (2001) também apresentam várias idades modelos Sm-Nd arqueanas, o que indica que parte da fonte do Complexo Sertânia deve ser uma crosta arqueana, ainda não reconhecida no Terreno Alto Moxotó.

A Tabela 3 apresenta diversas determinações Sm-Nd dos 


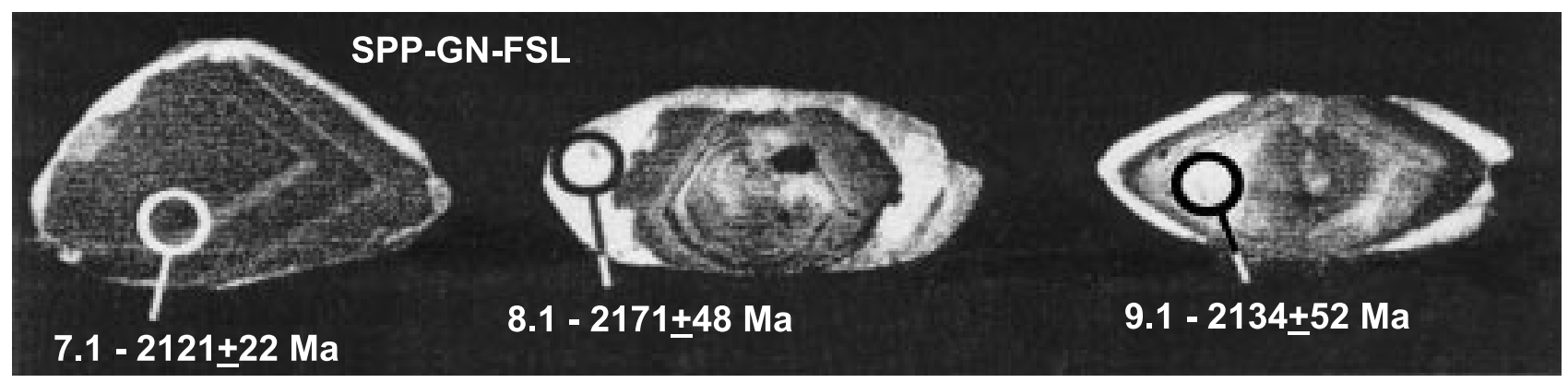

Foto 5. Cristais de zircão da amostra da Fazenda São Luís, exibindo a forma quase euédrica dos cristais e a zonação oscilatória paralela às bordas dos cristais. A foto ilustra também os locais de datação, variando de ca. 2121 até 2171 Ma.

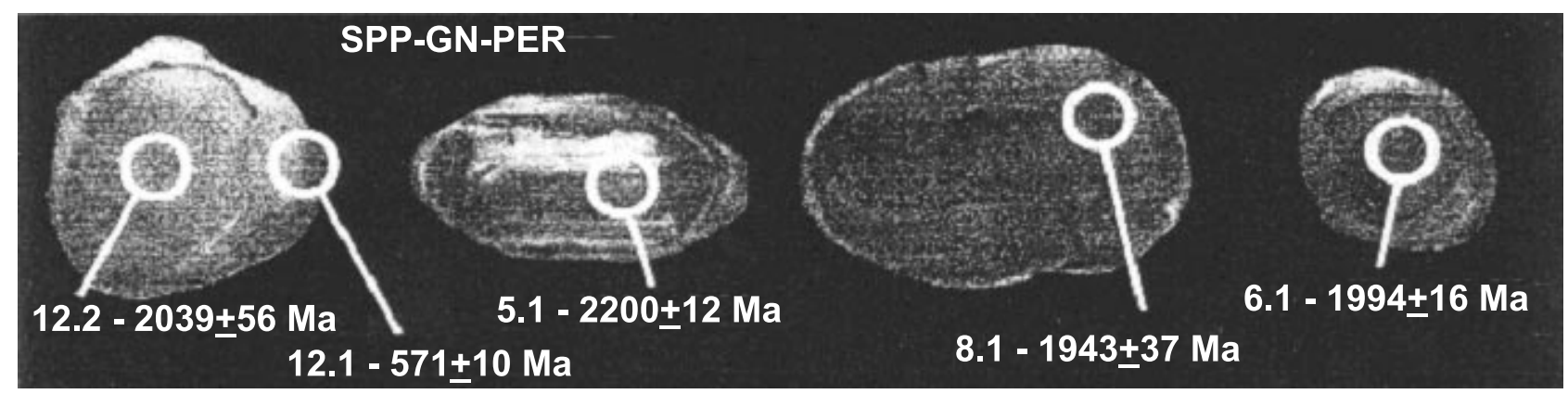

Foto 6. Cristais de zircão da amostra da Fazenda Pereiro, mostrando variado grau de arredondamento. O s cristais do meio ainda preservam um pouco das formas prismáticas originais. 0 grão da direita é subarredondado, mas a zonação oscilatória indica a forma antiga do cristal. São ilustrados ainda diversos pontos de datação, que indicam idades entre 2200 e 1994 Ma. O cristal da esquerda mostra um núcleo com ca. 2039 Ma e um sobrecrescimento brasiliano (ca. $571 \mathrm{Ma})$.

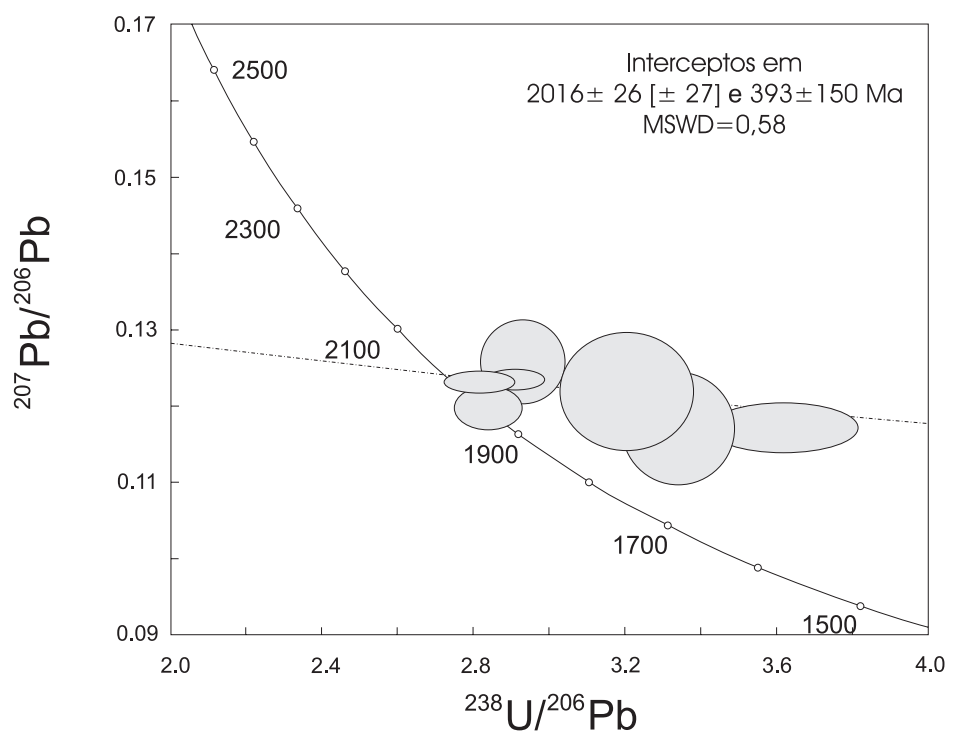

Figura 4. Diagrama concórdia U-Pb em zircão do ortognaisse de Barra de João Leite, com regressão das 8 análises (modelo 1), que indica uma idade de intercepto superior de $2016 \pm 26 \mathrm{Ma}$ e intercepto inferior de $393 \pm 150 \mathrm{Ma}$. 0 modelo 2, com as 4 análises mais concordantes (não ilustrado) forneceu uma regressão de $2008 \pm 21$ Ma. 
Tabela 2. Dados isotópicos Sm-Nd do Complexo Sertânia.

\begin{tabular}{|c|c|c|c|c|c|c|c|c|c|c|c|}
\hline Amostra & Sigla amostra & Localização & Rocha & $\begin{array}{c}\mathrm{Sm} \\
(\mathrm{ppm})\end{array}$ & $\begin{array}{c}\mathrm{Nd} \\
(\mathrm{ppm})\end{array}$ & $\begin{array}{c}{ }^{147} \mathrm{Sm} / \\
{ }^{144} \mathrm{Nd}\end{array}$ & $\begin{array}{l}{ }^{143} \mathrm{Nd} / \\
{ }^{144} \mathrm{Nd}\end{array}$ & Erro & $\begin{array}{c}\mathrm{T}_{\mathrm{DM}} \text { DePaolo } \\
(\mathrm{Ma})\end{array}$ & $\varepsilon_{\mathrm{Nd}(0)}$ & $\varepsilon_{\mathrm{Nd}(\mathrm{t})}$ \\
\hline 1 & SPP-Gn-Col & Caracolzinho & Bt gnaisse & 4.269 & 22.233 & 0,1161 & 0,511299 & 0,000012 & 2748,70 & $-26,12$ & $-5,56$ \\
\hline 2 & SPP-GN-FSL & Faz. São Luís & Xisto vulcanoc. & 3.116 & 15.576 & 0,1210 & 0,511637 & & 2319,50 & $-19,53$ & $-0,21$ \\
\hline 3 & SPP-GN-PER & Pereiro & Gran-biot xisto & 10.267 & 46.405 & 0,1338 & 0,511502 & & 2981,80 & $-12,16$ & $-6,11$ \\
\hline 4 & SPP-Bgx & W-Aroeiras & Sill-Bt gnaisse & 13.344 & 91.770 & 0,0879 & 0,511014 & 0,000010 & 2470,70 & $-31,68$ & $-3,93$ \\
\hline 5 & SPP-Gn-EITA & E-Itabaiana & Bt gnaisse & 6.416 & 36.281 & 0,1069 & 0,511169 & 0,000010 & 2696,40 & $-28,66$ & $-5,76$ \\
\hline 6 & SPP-Gn-WSSF & W-Salgado S. Felix & Bt gnaisse & 2.077 & 7.400 & 0,1697 & 0,512265 & 0,000036 & 2739,50 & $-7,28$ & $-0,39$ \\
\hline 7 & SPP-Gn-SERT3 & Sertânia (cidade) & Bt gnaisse & 31.473 & 226.723 & 0,0839 & 0,510938 & 0,000013 & 2484,70 & $-33,16$ & $-4,40$ \\
\hline
\end{tabular}

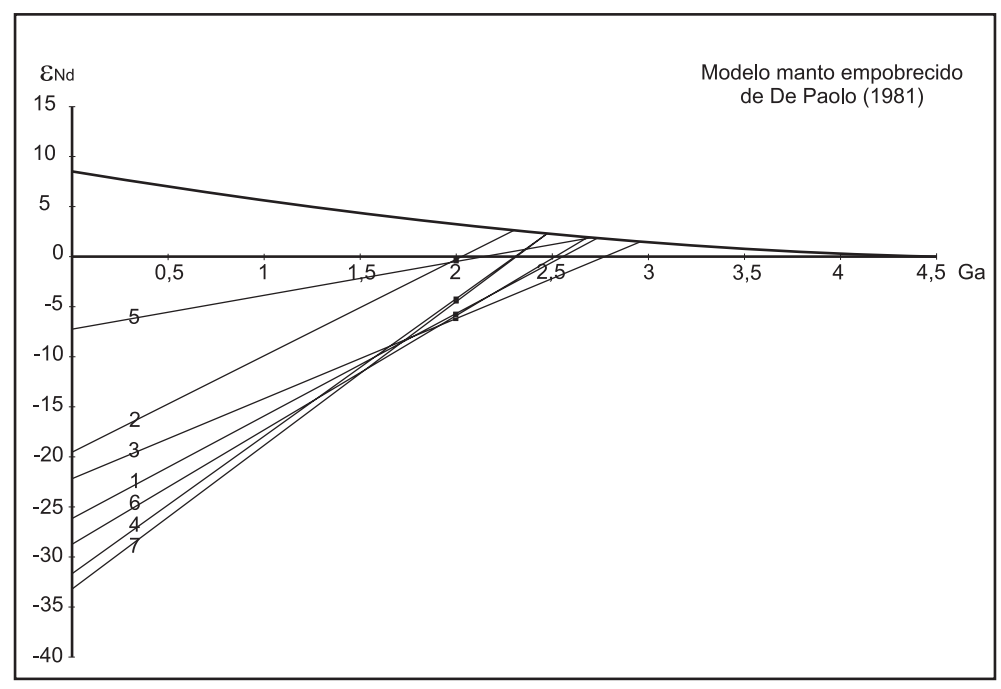

Figura 5. Diagrama de evolução isotópica $\boldsymbol{\varepsilon}_{\mathrm{Nd}}$ do Complexo Sertânia. As linhas de evolução 2 e 3 correspondem às amostras SPP-GN-PER e SPP-GN-FSL datadas por U-Pb SHRIMP no presente trabalho. Os dados analíticos estão na Tabela 2.

Tabela 3. Dados isotópicos $\mathrm{Nd}$ das rochas do Terreno Alto Moxotó. Os valores de $\boldsymbol{\varepsilon}_{\mathrm{Nd(t}}$ foram calculados para $2000 \mathrm{Ma}$. Dados compilados: 1 - Fernandes (1997); 2 - Dantas (1997); 3 - Brito Neves et al. (2001).

\begin{tabular}{|c|c|c|c|c|c|c|c|c|c|c|c|c|}
\hline Amostra & Coordenadas & Localidade & Rocha & $\mathrm{Sm}$ & $\mathrm{Nd}$ & ${ }^{147} \mathrm{Sm} /{ }^{144} \mathrm{Nd}$ & ${ }^{143} \mathrm{Nd} / /^{144} \mathrm{Nd}$ & Erro & $\varepsilon_{\mathrm{Nd}(\mathrm{t})}$ & $\varepsilon_{\mathrm{Nd}(0)}$ & TDM (Ma) & Fonte \\
\hline SCB-Gn-APA & $35^{\circ} 25^{\prime} 00^{\prime \prime} \mathrm{W} / 5^{\circ} 25^{\prime} 42^{\prime \prime} \mathrm{S}$ & Faz. Aparecida & Gnaisse & 31,43 & 17.400 & 0,1092 & 0,511439 & 0,000044 & $-23,39$ & $-1,07$ & 2349 & 1 \\
\hline SCB-Gn-CV & $35^{\circ} 13^{\prime} 20^{\prime \prime} \mathrm{W} 7^{\circ} 09^{\prime} 30^{\prime \prime} \mathrm{S}$ & Pedreira Sobrado & Gnaisse & 3,57 & 14,54 & 0,14837 & 0,511918 & 0,000008 & -14 & $-1,72$ & 2650 & 2 \\
\hline SCB-Mi-MIR & $35^{\circ} 10^{\prime} 52^{\prime \prime} \mathrm{W} / 6^{\circ} 57^{\prime} 12^{\prime \prime} \mathrm{S}$ & Rio Miriri & Migmatito & 3,841 & 18,411 & 0,1143 & 0,511518 & $-0,000012$ & $-21,85$ & $-3,85$ & 2348 & 3 \\
\hline SCB-Agn-41c & $35^{\circ} 36^{\prime} 29^{\prime \prime} \mathrm{W} / 7^{\circ} 09^{\prime} 14^{\prime \prime} \mathrm{S}$ & N Juarez Távora & Ortognaisse & 10,995 & 88,731 & 0,0749 & 0,511053 & 0,00001 & $-30,92$ & 0,15 & 2191 & 3 \\
\hline SCB-Gn-Zbi & $35^{\circ} 10^{\prime} 00^{\prime \prime} \mathrm{W} / 6^{\circ} 58^{\prime} 36^{\prime \prime} \mathrm{S}$ & Faz. Zumbi & Ortognaisse & 13,824 & 88,865 & 0,0997 & 0,511462 & 0,000013 & $-22,94$ & 3,24 & 2117 & 3 \\
\hline SPP-Mi-PTA & $37^{\circ} 01^{\prime} 00^{\prime \prime} \mathrm{W} / 7^{\circ} 47^{\prime} 50^{\prime \prime} \mathrm{S}$ & S Prata & Migmatito & 15,625 & 86,827 & 0,1088 & 0,510321 & 0,000014 & $-45,2$ & $-22,78$ & 4070 & 3 \\
\hline SCB-Gn-SMB & $35^{\circ} 12^{\prime} 42^{\prime \prime} \mathrm{W} / 7^{\circ} 01^{\prime} 37^{\prime \prime} \mathrm{S}$ & Samambaia & Ortognaisse & 22,59 & 43,887 & 0,3113 & 0,511616 & 0,000008 & $-28,8$ & - & 4300 & 3 \\
\hline SPP-Gn-PDS & $35^{\circ} 55^{\prime} 00^{\prime \prime} \mathrm{W} / 7^{\circ} 27^{\prime} 00^{\prime \prime} \mathrm{S}$ & Pedreira Soares & Gnd gnaisse & 3,97 & 27,8 & 0,08644 & 0,510874 & 0,000009 & -34 & $-6,28$ & 2610 & 2 \\
\hline SPP-Gn-13 & $35^{\circ} 58^{\prime} 21^{\prime \prime} \mathrm{W} / 7^{\circ} 27^{\prime} 16^{\prime \prime} \mathrm{S}$ & S Queimadas & Ortognaisse & 6,035 & 29,264 & 0,1247 & 0,511615 & 0,000015 & $-19,96$ & $-1,59$ & 2459 & 3 \\
\hline SCB-Gn-K44 & $35^{\circ} 30^{\prime} 00^{\prime \prime} \mathrm{W} / 7^{\circ} 12^{\prime} 20^{\prime \prime} \mathrm{S}$ & Km44 BR-230 & Gnaisse & 3,8 & 18,46 & 0,12436 & 0,511413 & 0,000007 & $-23,9$ & $-5,44$ & 2810 & 2 \\
\hline SCB-MI-ITB & $35^{\circ} 39^{\prime} 30^{\prime \prime} \mathrm{W} / 7^{\circ} 23^{\prime} 10^{\prime \prime} \mathrm{S}$ & W Itatuba & Gnaisse & 3,11 & 18,93 & 0,009976 & 0,51996 & 0,000009 & $-37,2$ & $-14,9$ & 2810 & 3 \\
\hline SCB-Ag-ITA2 & $35^{\circ} 39^{\prime} 30^{\prime \prime} \mathrm{W} / 7^{\circ} 23^{\prime} 10^{\prime \prime} \mathrm{S}$ & W Itatuba & Ortognaisse & 14,74 & 89,415 & 0,0996 & 0,511211 & 0,000011 & $-27,84$ & $-3,07$ & 2460 & 3 \\
\hline SCB-MI-JTV & $35^{\circ} 04^{\prime} 10^{\prime \prime} \mathrm{W} / 7^{\circ} 09^{\prime} 30^{\prime \prime} \mathrm{S}$ & N Juarez Távora & Migmatito & 4,24 & 25,98 & 0,9872 & 0,511346 & 0,000008 & $-25,2$ & $-0,21$ & 2260 & 2 \\
\hline SCB-Gn-GAV & $35^{\circ} 45^{\prime} 00^{\prime \prime} \mathrm{W} / 7^{\circ} 23^{\prime} 00^{\prime \prime} \mathrm{S}$ & Faz. Gavião & Migmatito & 1,88 & 9,68 & 0,11761 & 0,511605 & 0,00001 & $-20,2$ & 0,03 & 2290 & 2 \\
\hline SPP-Gn-SQ & $35^{\circ} 57^{\prime} 30^{\prime \prime} \mathrm{W} / 7^{\circ} 25^{\prime} 30^{\prime \prime} \mathrm{S}$ & Novo Horizonte & Gn tonalítico & 0,86 & 4,91 & 0,10649 & 0,511547 & 0,000009 & $-21,4$ & 1,73 & 2130 & 3 \\
\hline SPP-Gn-BVI & $36^{\circ} 14^{\prime} 32^{\prime \prime} \mathrm{W} / 7^{\circ} 15^{\prime} 34^{\prime \prime} \mathrm{S}$ & W Boa Vista & Gn granítico & 2,87 & 17,92 & 0,09682 & 0,511105 & 0,00001 & $-29,9$ & $-4,43$ & 2540 & 3 \\
\hline SPP-MI-BJL & $35^{\circ} 52^{\prime} 00^{\prime \prime} / \mathrm{W} 7^{\circ} 26^{\prime} 00^{\prime \prime} \mathrm{S}$ & Barra João Leite & Migmatito & - & - & 0,1171 & 0,51102 & - & $-31,56$ & $-11,26$ & 3245 & 3 \\
\hline
\end{tabular}


ortognaisses do Terreno Alto Moxotó, cujas idades modelos $\mathrm{T}_{\mathrm{DM}}$ variam de 2,1 até 2,8 Ga, confirmando a presença de protólitos arqueanos entre essas rochas.

A maioria dos dados $\mathrm{Rb}-\mathrm{Sr}$ dos ortognaisses alinha-se na isócrona de referência de $2190 \mathrm{Ma}$ (Brito Neves et al., 2001), confirmando a influência do evento Transamazônico neste terreno, diferentemente dos ortognaisses do Terreno Alto Pajeú, que invariavelmente possuem protólitos mesoproterozóicos e idade de geração/deformação Cariris Velhos. Raramente, o sistema $\mathrm{Rb}$-Sr dos ortognaisses retém a herança dos eventos anteriores, sendo o caso do ortognaisse de Barra do João Leite, que possui um protólito muito antigo (idade modelo com 3245 Ma e idade convencional $\mathrm{Rb}-\mathrm{Sr}$ de $3500 \mathrm{Ma}$ ).

\section{DISCUSSÃO E CONCLUSÕES}

De acordo com a definição do Terreno Alto Moxotó (Santos, 1996, 1999), distingue-se nele dois constituintes litoestratigráficos principais: uma unidade metaplutônica dominante, em parte, equivalente do Complexo Floresta; e uma unidade supracrustal, o Complexo Sertânia, objeto do presente trabalho. Esta última unidade foi individualizada há vários anos na região de Arcoverde (PE) (Santos, 1971, 1977), utilizando-se as técnicas de mapeamento disponíveis para a época, que envolveram a individualização de diversas sequiências litoestratigráficas, com base na identificação do protólito dos migmatitos. No entanto, inexistiam, até o presente, determinações geocronológicas deste complexo metassedimentar.

Levantamentos geológicos recentes e a análise geotectônica, com apoio de dados geocronológicos U-Pb e Sm-Nd e aerogeofísicos, têm permitindo entender melhor os mecanismos de amalgamação dos terrenos que compõem o mosaico crustal da Província Borborema (Brito Neves et al., 2000). Os dados aqui apresentados apontam para a identidade litoestratigráfica do Complexo Sertânia e o conceito do Terreno Alto Moxotó, como uma unidade e um segmento crustal distintos dos elementos adjacentes, no âmbito da Zona Transversal. No entanto, as idades obtidas mostram que os zircões do Complexo Sertânia possuem a mesma idade do Complexo Floresta, o que implica em duas possibilidades:

1. as idades obtidas representam idades de formação, sendo os dois complexos membros distintos de um mesmo ciclo de evolução crustal pré-Cariris Velhos;

2. as idades dos zircões das supracrustais estariam refletindo a fonte dos sedimentos, de modo que os zircões do Complexo Sertânia seriam zircões herdados do Complexo Floresta.
A falta de espalhamento das frações de zircão das supracrustais no diagrama Tera-Wasserburg e a morfologia desses cristais apontam para uma fonte ígnea homogênea, proximal, o que pode implicar numa formação penecontemporânea do Complexo Sertânia com o Complexo Floresta. As idades modelos $\mathrm{Nd}_{\mathrm{DM}}$ das duas unidades são similares, indicando fontes idênticas, o que seria coerente com ambas as hipóteses acima, posto que as vulcanoclásticas poderiam herdar a assinatura isotópica da fonte metaplutônica. No entanto, tem-se noticiado a existência de eventos plutônicos anorogênicos de idades entre 1,7 e 1,5 Ga em terrenos congêneres do Complexo Floresta (Santos \& Medeiros, 1999) e nenhuma idade deste intervalo foi encontrado entre os zircões do Complexo Sertânia. Além disso, as idades modelos $\mathrm{Nd} \mathrm{T}_{\mathrm{DM}}$ de típicas seqüências supracrustais Cariris Velhos no Terreno Alto Pajeú, o Complexo São Caetano, são todas mesoproterozóicas, com uma grande incidência no intervalo entre 1,5 e 1,2 Ga (Brito Neves et al., 1995), diferentemente das supracrustais aqui estudadas, o que demonstra tratarem-se de sistemas sedimentares distintos.

Não obstante, recentes investigações quimioestratigráficas realizadas na parte leste da Zona Transversal têm levantado a hipótese de que o Complexo Sertânia possa ser uma unidade Cariris Velhos. Segundo V. H. Santos et al. (2002), os padrões de $\delta^{13} \mathrm{C}$ dos mármores dos complexos Surubim-Caroalina (unidade do Terreno Rio Capibaribe) e Sertânia são idênticos e compatíveis com uma idade de deposição em torno de $900 \mathrm{Ma}$, utilizando-se a comparação com a curva de variação secular do $\delta^{13} \mathrm{C}$. As idades isocrônicas $\mathrm{Pb}-\mathrm{Pb}$ obtidas para os mármores desses complexos foram, respectivamente, de $887 \pm 20$ Ma e $822 \pm 130$ $\mathrm{Ma}$, interpretadas como idade do metamorfismo Cariris Velhos, que sucedeu imediatamente a deposição das duas seqüências.

Levanta-se aqui a possibilidade de um reequilíbrio isotópico dos sistemas $\mathrm{C}$ e $\mathrm{Pb}-\mathrm{Pb}$, devido ao forte aquecimento imposto pelo metamorfismo de facies anfibolito médio a alto que afetou ambas as sequiências. As idades obtidas por estes autores poderiam estar refletindo, tão somente, a presença do evento metamórfico Cariris Velhos em ambos os terrenos e não a idade da deposição das duas sequiências. No caso do Complexo Sertânia, a idade da deposição estaria sendo calibrada pelas datações U-Pb SHRIMP em zircão aqui apresentadas. Por isso, sugerimos a realização de datações U-Pb do Complexo Surubim-Caroalina, para confrontar com as idades $\mathrm{Pb}-\mathrm{Pb}$ acima referidas.

Pelos dados atuais, portanto, nossa interpretação é de que o Complexo Sertânia representa uma unidade litoestratigráfica paleoproterozóica distinta das supracrustais dos terrenos Alto Pajeú, Rio Capibaribe e das faixas Riacho Gravatá e Cachoeirinha, cujas supracrustais são de idade Cariris Velhos e Brasiliana. 


\section{REFERÊNCIAS BIBLIOGRÁFICAS}

BRITO NEVES, B. B. Regionalização geotectônica do Précambriano nordestino. 1975. 198 f. Tese (Doutorado) Instituto de Geociências, Universidade de São Paulo.

BRITO NEVES, B. B.; VAN SCHMUS, W. R.; SANTOS, E. J.; CAMPOS NETO, M. C.; KOZUCH, M. O evento Cariris Velhos na Província Borborema. Revista Brasileira de Geociências, v. 25, p. 279-296, 1995.

BRITO NEVES, B. B.; SANTOS, E. J.; VAN SCHMUS, W. R. Tectonic history of the Borborema Province. In: CORDANI, U. G. et al. Tectonic evolution of the South America. Rio de Janeiro: $31^{\text {st }}$ International Geological Congress, 2000. p.151-182.

BRITO NEVES, B. B.; CAMPOS NETO, M. C.; VAN SCHMUS, W. R.; FERNANDES, T. M. G.; SOUZA, S. L. O terreno Alto Moxotó no leste da Paraíba ("Maciço Caldas Brandão"). Revista Brasileira de Geociências, v. 31, n. 2, p. 185-194, 2001.

COMPSTON, W.; WILLIAMS, I. S.; MYER, C. U-Pb geochronology of zircons from lunar breccia 73217 using a sensitive high mass-resolution ion microprobe. Journal of Geophysical Research, v. 89B, p. 525-534, 1984.

CUMMING, G. L.; RICHARDS, J. R. Ore lead ratios in a continuously changing earth. Earth Planetary Science Letters, v. 28, p. 155-171, 1975.

GOMES, J. R. C.; GATTO, C. M .P. P.; SOUZA, G. M. C.; LUZ, D. S.; PIRES, J. L.; TEIXEIRA, W. Geologia. In: Projeto RADAMBRASIL. Folha SB. 24/25, Jaguaribe/ Natal. Rio de Janeiro: MME, 1980. (Levantamento de Recursos Naturais, 23).

JARDIM DE SÁ, E. F. A Faixa Seridó (Província Borborema, NE do Brasil) e o seu significado geodinâmico na cadeia brasiliana/panafricana. 1994. 803 f. Tese (Doutorado) - Universidade de Brasilia.

LUDWIG, K. R. Isoplot/Ex. Berkeley: Geochronology Center, 1998. (Special Publication, 1).

PACES, J. B.; MILLER JR, J. D. Precise U-Pb ages of Duluth Complex and related mafic intrusions, northeastern Minnesota: Geochronological insights to physical, petrogenetic, paleomagnetic, and tectonomagmatic processes associated with the $1.1 \mathrm{Ga}$ midcontinent rift system. Journal Geophysical Research, v. 98, p. 13997-14013, 1993.

SANTOS, E. J. Síntese da geologia do Pré-cambriano da folha Arcoverde - nordeste do Brasil. Recife: SUDENE, $1971.33 \mathrm{p}$.

SANTOS, E. J. Síntese da geologia pré-cambriana da folha Arcoverde, Pernambuco. In: SIMPÓSIO DE GEOLOGIA DO NORDESTE, 8., 1977. Campina Grande. Atas. Campina Grande: SBG, 1977. p. 225-245.

SANTOS, E. J. Ensaio preliminar sobre terrenos e tectônica acrescionária na Província Borborema. In: CONGRESSO
BRASILEIRODE GEOLOGIA, 39., 1996. Salvador.Anais. Salvador: SBG, 1996. v. 6, p. 47-50.

SANTOS, E. J. Belém do São Francisco, folha SC. 24-X-A: estados de Pernambuco, Alagoas e Bahia, Brasília CPRM, 1999. 84p. (Programa de Levantamentos Geológicos Básicos do Brasil). 1 CD-ROM

SANTOS, E. J.; MEDEIROS, V. C. Constraints from granitic plutonism on Proterozopic crustal growth of the Transverse Zone, Borborema Province, NE Brazil. Revista Brasileira de Geociências, v. 29, p. 73-84, 1999.

SANTOS, E. J.; FERREIRA, C. A. ; SILVA JR., J. M. Geologia e recursos minerais do estado da Paraíba. Paraíba: CPRM, 2002. 142p. (Programa de Levantamentos Geológicos Básicos do Brasil).

SANTOS, V. H.; FERREIRA, V.P.; SIAL, A. N.; BABINSKI, M.; PIMENTEL, M. M. C. Pb and $\mathrm{Sr}$ isotopic chemostratigraphy in Proterozoic carbonate sequences in the eastern Transversal domain of the Borborema Province, Northeast Brazil. In: CONGRESSO BRASILEIRO DE GEOLOGIA, 41., 2002. João Pessoa. Anais. João Pessoa: SBG - Núcleo Nordeste, 2002. p. 509.

STEIGER, R. H.; JÄGER, E. Subcommission on geochronology: convention on the use of decay constants in geoand chosmochronology. Earth Planetary Science Letters, v. 36, p. 359-362, 1977.

STERN, R. A. High resolution SIMS determination of radiogenic trace isotope ratios in minerals. In: CABRI, L. J.; VAUGHAN, D. J. (Eds) Modern approaches to ore and environmental mineralogy. Ottawa: Mineralogical Association of Canada, 1998. p.241-268. (Canada Short Course Series, Mineralogical Association of Canada, v. 27).

VAN SCHMUS, W. R.; BRITO NEVES, B. B.; HACKSPACHER, P.; BABINSKI, M. U/Pb and $\mathrm{Sm} / \mathrm{Nd}$ geochronological studies of eastern Borborema Province, northeastern Brazil: initial conclusions. Journal of South American Earth Sciences, v. 8, n. 3-4, p. 267-288, 1995.

VEIGA JR, J. P.; FERREIRA, C. A. Afogados da Ingazeira, folha SB. 24-Z-C-VI: estados de Pernambuco e Paraíba. Brasília: DNPM/CPRM, 1990. 121p. (Programa de Levantamentos Geológicos Básicos do Brasil).

WANDERLEY, A. A. Monteiro, folha SB. 24-Z-D-IV: estados de Pernambuco e Paraíba. Brasília: DNPM/CPRM, 1990. 100p. (Programa de Levantamentos Geológicos Básicos do Brasil).

WILLIAMS, I. S. U-Th-Pb Geochronology by Ion Micropobe. In: McKIBBEN, M. A.; SHANKS III, W. C.; RIDLEY, W. I. Applications of Microanalytical Techniques to Understanding Mineralizing Processes. Society of Economic Geologists, v. 7, p. 1-35, 1998. 